\title{
HER-2/Neu Status in Gastric Carcinomas in a Series of Egyptian Patients and Its Relation to Ki-67 Expression
}

\author{
Saba El-Gendi, Iman Talaat, Mona Abdel-Hadi \\ Department of Pathology, Faculty of Medicine, Alexandria University, Alexandria, Egypt \\ Email: monaabd@hotmail.com
}

Received 20 July 2015; accepted 14 August 2015; published 17 August 2015

Copyright (C) 2015 by authors and Scientific Research Publishing Inc. This work is licensed under the Creative Commons Attribution International License (CC BY). http://creativecommons.org/licenses/by/4.0/

(c) (i) Open Access

\section{Abstract}

Objective: HER-2/neu status in gastric carcinomas (GCs) has not been studied before in the Egyptian population. Materials and Methods: Seventy-three GCs were evaluated for the expression of HER-2/neu and Ki-67 using immunohistochemistry (IHC). Fluorescence in situ Hybridization (FISH) was done for HER2/neu IHC score 2+ cases. Results: Out of the 73 gastric carcinomas, 23 (31.5\%) were score $0,17(23.3 \%)$ were score $1+, 23(31.5 \%)$ were score $2+$, and $10(13.7 \%)$ were score $3+$. FISH analysis revealed that the HER-2/neu gene was amplified in 11 out of the 23 cases (47.8\%) scored $2+$ by IHC. Therefore, the overall HER-2/neu positivity rate was $28.8 \%$ and it was significantly associated with higher T-stage and lymphovascular invasion (LVI). The Ki-67 expression rate ranged between $10 \%$ and $100 \%$, with $84.9 \%$ of the cases $(n=62)$ featuring high Ki-67 scores. High Ki-67 score was significantly associated with male sex, tumor grade, and number of positive nodes. HER-2/neu protein expression correlated significantly with Ki-67 score. Twenty tumors showed combined HER-2/neu positivity and high Ki-67 score and were significantly associated with higher T-stage and occurrence of LVI, implying a more aggressive behavior. Conclusions: The rate of HER-2/neu positive GCs in our series simulates universal rates, thereby mandating routine evaluation of HER-2/neu status in all GCs submitted to our laboratory to benefit from trastuzumab therapy. Further studies on a larger number of GCs are required to prove that the concurrent HER-2/neu positivity and high Ki-67 score are markers of worse prognosis.

\section{Keywords}

Egypt, FISH, Gastric Carcinoma, HER-2/Neu, Immunohistochemistry, Ki-67 


\section{Introduction}

Gastric carcinoma (GC) contributes to $10 \%$ of cancer deaths worldwide with a case of fatality ratio of $70 \%$ [1]. According to the Egyptian National Cancer Institute, GC in both sexes represented $1.8 \%$ of the total cancers in the period from 2002 to 2010 [2]. And according to the Globocan 2012, the estimated GC cumulative risk incidence among all ages and both sexes in Egypt is $0.3 \%$, while the estimated cumulative mortality risk is $0.26 \%$ [3].

The pathogenesis of gastric cancer involves dietary, infectious, occupational, genetic and preneoplastic risk factors. A long-lasting chronic gastritis initiates a cascade of reactive changes; whereby the normal gastric mucosa is transformed to chronic atrophic gastritis and develops multifocal atrophy and intestinal metaplasia, followed by the appearance of dysplasia and finally invasive carcinoma. However, evidence is lacking for an equivalent sequence of events in the diffuse-type gastric cancer, a key step in the development of which is the loss of E-cadherin, despite the common development on a background of increased regenerative processes [4].

Introducing new therapies in the treatment of $\mathrm{GC}$ is imperative as the currently available chemotherapeutics are not very effective [5].

Human epidermal growth factor receptor 2 (coded by the ERBB2 gene) gain of function is associated with increased cell motility, invasiveness, angiogenesis, resistance to apoptosis, and metastatic potential [6]. A metaanalysis showed that the overall prevalence of HER2/neu overexpression in GCs was 19\% [7].

The multinational trastuzumab for gastric cancer (ToGA) clinical trial demonstrated increased survival in HER-2/neu-over expressing GCs when trastuzumab was added to conventional treatment [8].

In addition, the prognosis of patients with GC can be influenced by the alteration of oncogenes or tumor suppressor genes, determining alterations of the kinetics of cell proliferation [9]. Ki-67 is a nuclear non-histone protein, which is required for maintaining the cell cycle [10]. Ki-67 monoclonal antibodies detect a nuclear antigen expressed exclusively in the G1, S, G2 and mitosis phases of the cell cycle, making this antigen an excellent marker for determining the proliferation of a given cell population and the aggressiveness of malignancies [11].

Although HER-2/neu testing on breast cancer is a routine in our hospital, its testing on GC is not routinely done. By this study we aimed at determining the frequency of HER-2/neu positive GC in our hospital which was a referral center in the city of Alexandria, intending to make the assessment of HER-2/neu status as well as the treatment by trastuzumab a standard of care among our patients. We also aimed to determine whether the expression of HER-2/neu was associated with a more aggressive behavior by its correlation with Ki-67 expression.

\section{Materials \& Methods}

This study was approved by Alexandria University, Faculty of Medicine Research Ethics Committee. Seventy-three cases of gastrectomy (whether total or partial) for carcinomas were retrieved retrospectively from the archives of the Pathology department between January 2009 and December 2013. Cases were consecutively accrued with exclusion of patients who received neoadjuvant chemotherapy or radiotherapy and those for whom complete clinical information was lacking. Data about age and sex of the patients, anatomical site of the tumors, lymph node status as well as details of gross examination were obtained from the clinical sheets and pathology reports. All microscopic slides of each case were reviewed and the most representative section with the maximum tumor bulk was selected for immunohistochemistry (IHC) and fluorescence in situ hybridization (FISH) analysis. The corresponding tissue block was retrieved and 5 micron sections were cut from each block, one for Hematoxylin and Eosin staining and 3 sections on coated slides for IHC and FISH.

\subsection{Histopathology}

All H\&E sections were reviewed for tumor typing and grading according to the WHO classification system of gastrointestinal tumors [12]. The pathological stage of the tumor was established according to the 7th Edition of the AJCC Cancer Staging system [13]. Further data were also recorded such as lymphovascular invasion (LVI), the presence of mucin pools, signet ring cells as well as the presence of necrosis.

\subsection{Immunohistochemical Staining}

Both primary antibodies were purchased from Lab Vision Corporation (Neo Markers, Fremont, USA); HER-2/c- 
erbB-2/neu Ab-17, mouse monoclonal antibody (diluted at 1:200) and Ki-67, RM-9106-S0, rabbit monoclonal antibody (diluted at 1:200). The detection system kit (UltraVision detection system) was purchased from Lab Vision Corporation (Neo Markers, Fremont, USA).

The immunostaining procedure was done following the streptavidin-biotin-immunoenzymatic antigen detection method, performed according to the manufacturer's protocol. Slides were deparaffinized, rehydrated, and heated in a microwave oven containing $0.01 \mathrm{~mol} / \mathrm{L}$ citrate buffer $(\mathrm{pH} 6.0)$ for $10 \mathrm{~min}$ at $100^{\circ} \mathrm{C}$ for antigen retrieval, cooled for $20 \mathrm{~min}$ and washed with a buffer solution. Peroxidase was then applied for 5 min and washed twice with a buffer solution for $5 \mathrm{~min}$. Primary antibodies were then applied overnight. The antigen antibody reaction was visualized by the UltraVision detection system. Immunohistochemical reactions were developed with diaminobenzidine and sections counterstained with Harris hematoxylin. Negative controls (where the primary antibody has been omitted) were included in all runs. Appropriate positive controls (breast carcinoma for HER-2/neu and colonic carcinoma for Ki-67) were also included in all runs.

\subsection{Scoring of HER-2/Neu IHC}

The samples were analyzed using standard criteria for HER-2/neu positivity. Positivity was assessed as brown cell membrane staining of malignant cells. All slides were scored independently by the 3 authors according to the Gastric Cancer Scoring System (GCSS) for Surgical Specimens [14] as follows:

Score 0 negative: No staining or membrane staining in $<10 \%$ of invasive tumor cells.

Score $1+$ /negative: Faint/barely perceptible membrane staining in $\geq 10 \%$ of invasive tumor cells; cells are only stained in part of their membranes.

Score $2+$ equivocal: Weak to moderate complete or basolateral membrane staining in $\geq 10 \%$ of invasive tumor cells.

Score 3+/positive: Moderate to strong complete or basolateral membrane staining in $\geq 10 \%$ of invasive tumor cells.

All the cases that were given a score of 2+ were further assessed using FISH.

\subsection{Fluorescence in Situ Hybridization Evaluation}

FISH was performed using the US FDA approved Path Vysion ${ }^{\circledR}$ HER-2/neu DNA Probe (Vysis $\{$ Abbott $\}$ Molecular Inc., Des Plaines, IL, USA), which is a dual-colored probe comprising a locus specific identifier (LSI) HER-2/neu Spectrum Orange which spans HER-2/neu and a centromere enumeration probe (CEP) 17 Spectrum Green which hybridizes to the alpha satellite DNA located at the centromere of the chromosome. The test was carried out on thin paraffin sections using the paraffin pretreatment reagent kit II (Vysis Inc.). FISH procedure was carried out as per manufacturer's instructions in package insert. Briefly, samples were deparaffinized and pretreated to maximize tissue permeability and hybridization. After denaturation of both DNA sample and probe, hybridization of the probe to its target DNA took place. After hybridization, unbound probe was removed via rapid wash procedure followed by application of counterstain to detect the cell nucleus. Analysis was performed via enumeration of probe signals within the cell nuclei. Hybridization procedure was performed using co-hybridization method using the HYbrite Denaturation/Hybridization Unit (VysisInc). The melt temperature of the HYbrite system was set to $73^{\circ} \mathrm{C}$ and the melt time to 5 minutes. The hybridization temperature was set to $37^{\circ} \mathrm{C}$ and the hybridization time to 20 hours.

FISH signals were analyzed using BX51/61 Olympus fluorescent microscope equipped with a suitable set of filters including: DAPI single band pass, dual band pass FITC/TRITC and triple band pass (FITC/TRITC/DAPI) (Olympus, UK LTD). The fluorescent microscope is attached to a digital camera and results were interpreted using cytovision FISH software (Applied Imaging). The fields containing invasive tumor component with nonoverlapping tumor nuclei with clearly visible distinct signals were chosen for interpretation. A minimum of 100 interphase nuclei for each case were counted. The total number of red and green signals counted in the nuclei was recorded and then ratio of the HER-2/neu (red) to CEP 17 (green) signals was calculated. Fields showing excess background signals or auto-fluorescence masking the nuclear signals were not evaluated. A ratio of HER$2 /$ neu to CEP17 signals $\geq 2$ was reported as amplification, a ratio $<2$ was reported as non-amplification, while a ratio at or near the cutoff point (1.8 and 2.2) was taken as an equivocal result. A recounting of additional 20 tumor nuclei was done for the equivocal cases. 


\subsection{Scoring of Ki-67 IHC}

The samples were analyzed following the recommendations from the International Ki-67 in Breast Cancer Working Group [15]; whereby positive Ki-67 staining was defined as only positive nuclear staining, regardless of the staining intensity. Scoring involved the counting of at least 1000 nuclei at high-power $(\times 40$ objective). The Ki-67 score (Ki-67 index or proliferation index) was expressed as the percentage of positively staining nuclei among the total number of nuclei in the area scored.

For proper grouping of results, cases were then categorized into: GCs with high Ki-67 score $(>20 \%)$ and GCs with low Ki-67 score $(\leq 20 \%)[9]$.

\subsection{Statistical Analysis}

The raw data were coded and entered into the Statistical Package for Social Sciences (SPSS/version 20) SPSS system files (SPSS package version 18). Analysis and interpretation of data were conducted.

Quantitative data were described using the median (Mdn), minimum and maximum as well as the mean (M) and standard deviation (SD). Qualitative data were described using the number and percentage. Univariate analyses including: Mann Whitney test and Kruskal Wallis test were used to test the significance of results of quantitative variables. Chi-Square test and Fisher's exact test were used to test the significance of results of qualitative variables. Linear correlation was conducted using Spearman Rho correlation coefficient to show correlation between HER-2/neu IHC and Ki-67 among the studied patients. The significance of the results was at the 5\% level of significance.

\section{Results}

This study included 73 gastric carcinoma cases (41 males and 32 females). Patients' age ranged from 23 to 81 years with a mean age of $51.6 \pm 12.1$ years. The clinical and pathological features of the 73 cases included in the present series are shown in Table 1.

\subsection{Immunohistochemical Study of HER-2/Neu Protein Expression}

Out of the 73 gastric carcinomas included in the study, 23 (31.5\%) were score 0,17 (23.3\%) score 1+, 23 $(31.5 \%)$ score $2+$, and $10(13.7 \%)$ were score $3+$. HER-2/neuimmunoreactivity was weaker or absent in mucinous foci of intestinal type gastric carcinoma. Lymphovascular neoplastic emboli featured HER-2/neu immunostaining similar to the primary tumor.

\subsection{HER-2/Neu Gene Amplification Study by FISH}

HER-2/neu gene amplification was analyzed by FISH in the 23 cases scored $2+$ by IHC. HER-2/neu gene was amplified in 11 out of the 23 cases (Figure 1), two cases revealed equivocal FISH results, and ten cases showed no amplification (Figure 2). The positive amplification rate of HER-2/neu gene among the HER2-neu IHC score $2+$ cases was $47.8 \%$.

After FISH analysis, 21 cases were HER-2/neu positive, thereby attaining an overall positivity rate of $28.8 \%$.

\subsection{Relationship between HER-2/Neu Status and the Different Clinicopathological Parameters}

A statistically significant relation was found between HER-2/neu positivity (IHC $3+$ / IHC $2+$ FISH positive) and the pathologic T-stage (T1, 2vs T3, 4) $(\mathrm{P}=0.026)$ as well as between HER-2/neu positivity and the presence of LVI $(P=0.02)$. No statistically significant relationship was found between HER-2/neu positivity and any of the other clinicopathological parameters (Table 2).

Out of the ten HER-2/neu IHC 3+ cases, nine (90\%) were intestinal-type carcinomas (Figure 3) and one case was mixed-type carcinoma (Figure 4(a)). None of the diffuse type was HER-2/neu IHC 3+. Out of the 11 FISH positive cases, eight $(72.7 \%)$ were intestinal-type and three $(27.3 \%)$ were diffuse carcinomas. Hence, out of the 21 HER-2/neu positive cases, 17 (81\%) were intestinal-type, three were diffuse (14.3\%) and one (4.7\%) was mixed-type carcinoma. 
Table 1. Clinicopathologic characteristics of the 73 studied gastric carcinomas.

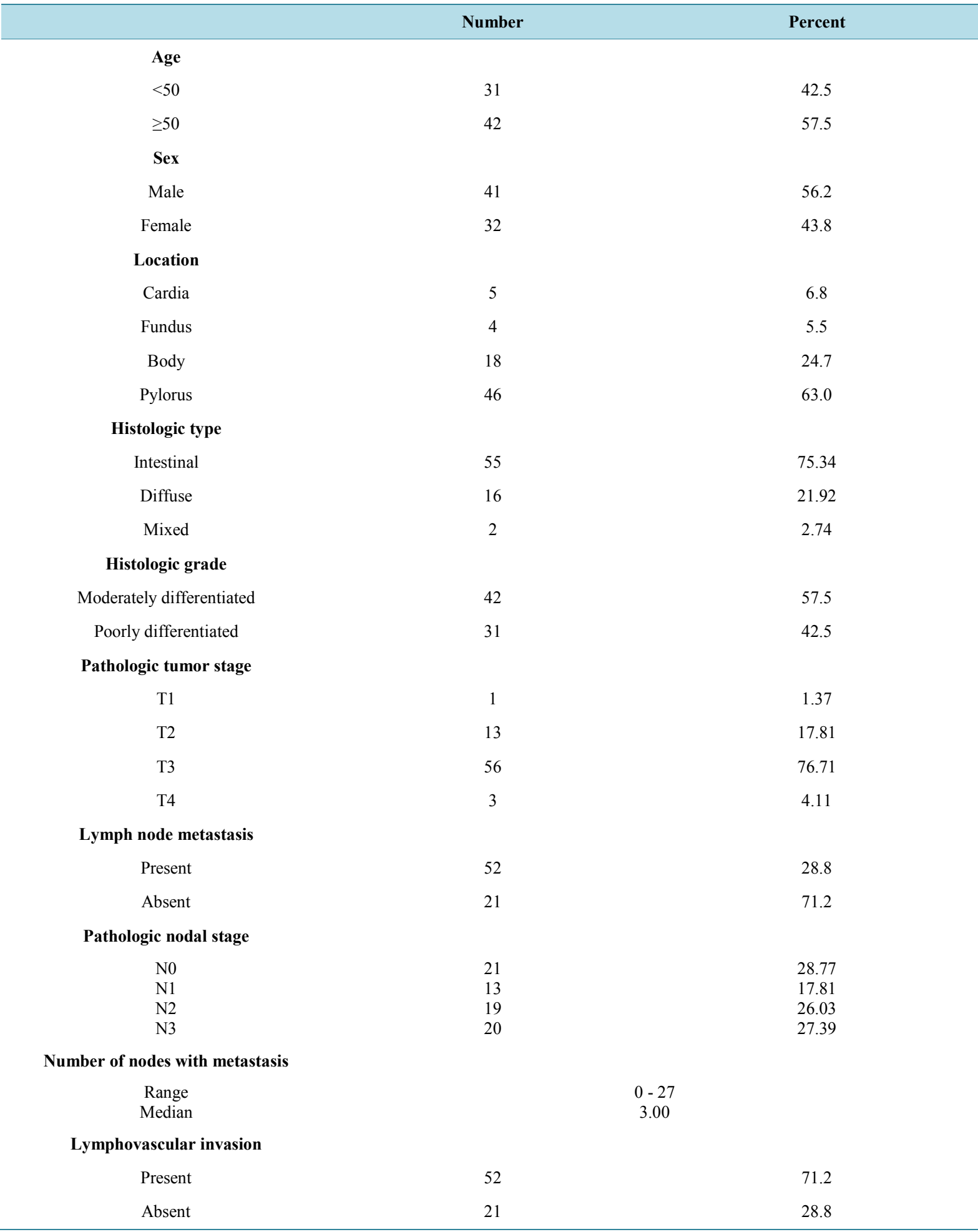

\subsection{Immunohistochemical Study of Ki-67 Expression}

Various Ki-67 scores were obtained ranging in distribution between $10 \%$ and $100 \%$, with $15.1 \%$ of the cases $(n=11)$ featuring low Ki-67 scores and $84.9 \%$ of the cases $(n=62)$ featuring high Ki-67 scores. It was noticed 
Table 2. Relation between HER-2/neu status and clinicopathological variables in the 71 studied cases (after excluding the two cases that were equivocal by FISH).

\begin{tabular}{|c|c|c|c|c|c|}
\hline & \multicolumn{4}{|c|}{ HER-2/neu } & \multirow{3}{*}{$\begin{array}{c}\text { Test } \\
\text { significance }\end{array}$} \\
\hline & \multicolumn{2}{|c|}{ Positive } & \multicolumn{2}{|c|}{ Negative } & \\
\hline & Number & $\%$ & Number & $\%$ & \\
\hline \multicolumn{6}{|l|}{ Age } \\
\hline$<50$ & 10 & 47.6 & 21 & 42.0 & \multirow{2}{*}{$\begin{array}{c}0.19^{\dagger} \\
\mathrm{P}=0.430\end{array}$} \\
\hline$\geq 50$ & 11 & 52.4 & 29 & 58.0 & \\
\hline \multicolumn{6}{|l|}{ Sex } \\
\hline Male & 14 & 66.7 & 27 & 54.0 & \multirow{2}{*}{$\begin{array}{c}0.432^{\dagger} \\
\mathrm{P}=0.236\end{array}$} \\
\hline Female & 7 & 33.3 & 23 & 46.0 & \\
\hline \multicolumn{6}{|l|}{ Histologic type } \\
\hline Intestinal & 17 & 81.0 & 37 & 74.0 & \multirow{3}{*}{$\begin{array}{c}1.155^{\ddagger} \\
\mathrm{P}=0.561\end{array}$} \\
\hline Diffuse & 3 & 14.3 & 12 & 24.0 & \\
\hline Mixed & 1 & 4.8 & 1 & 2.0 & \\
\hline \multicolumn{6}{|l|}{ Histologic grade } \\
\hline Moderately differentiated & 12 & 57.1 & 30 & 60.0 & \multirow{2}{*}{$\begin{array}{c}0.05^{\dagger} \\
\mathrm{P}=0.514\end{array}$} \\
\hline Poorly differentiated & 9 & 42.9 & 20 & 40.0 & \\
\hline \multicolumn{6}{|l|}{ Pathologic tumor stage } \\
\hline $\mathrm{T} 1, \mathrm{~T} 2$ & 1 & 4.8 & 12 & 24.0 & \multirow{2}{*}{$\begin{array}{c}4.95^{\ddagger} \\
\mathbf{P}=\mathbf{0 . 0 2 6}^{*}\end{array}$} \\
\hline $\mathrm{T} 3, \mathrm{~T} 4$ & 20 & 95.2 & 38 & 76.0 & \\
\hline \multicolumn{6}{|l|}{ Lymph node metastasis } \\
\hline Present & 16 & 76.2 & 34 & 68.0 & \multirow{2}{*}{$\begin{array}{c}0.476^{\dagger} \\
\mathrm{P}=0.348\end{array}$} \\
\hline Absent & 5 & 23.8 & 16 & 32.0 & \\
\hline \multicolumn{6}{|l|}{ Pathologic nodal stage } \\
\hline No & 5 & 23.8 & 16 & 32.0 & \multirow{4}{*}{$\begin{array}{c}3.208^{\dagger} \\
\mathrm{P}=0.361\end{array}$} \\
\hline N1 & 2 & 9.5 & 10 & 20.0 & \\
\hline $\mathrm{N} 2$ & 8 & 38.1 & 10 & 20.0 & \\
\hline N3 & 6 & 28.6 & 14 & 28.0 & \\
\hline \multicolumn{6}{|c|}{ Number of nodes with metastasis } \\
\hline $\begin{array}{l}\text { Range } \\
\text { Median }\end{array}$ & \multicolumn{2}{|c|}{$\begin{array}{c}0-14 \\
4.5\end{array}$} & \multicolumn{2}{|c|}{$\begin{array}{c}0-27 \\
5.5\end{array}$} & $\begin{array}{c}0.24^{\S} \\
\mathrm{P}=0.625\end{array}$ \\
\hline \multicolumn{6}{|l|}{ Lymphovascular invasion } \\
\hline Present & 19 & 90.5 & 32 & 64.0 & \multirow{2}{*}{$\begin{array}{c}5.12^{\ddagger} \\
\mathbf{P}=\mathbf{0 . 0 2 0}\end{array}$} \\
\hline Absent & 2 & 9.5 & 18 & 36.0 & \\
\hline
\end{tabular}

"Significant at $\mathrm{P} \leq 0.05 ;{ }^{\dagger} \mathrm{Chi}$ Square test; ${ }^{\star}$ Fisher exact test; ${ }^{\S}$ Mann Whitney U test.

that the two mixed-type carcinomas revealed high Ki-67 scores, with higher proliferation index in the diffuse compared to the intestinal component.

\subsection{Relationship between Ki-67 Expression and the Different Clinicopathological Parameters}

A significantly greater frequency of adenocarcinomas with high $\mathrm{Ki}-67$ score was noted in male patients $(61.3 \%$; $\mathrm{P}=0.039)$. A high Ki-67 score correlated significantly with higher tumor grade $(\mathrm{P}=0.014)$, and greater number of regional nodes featuring metastatic deposits $(\mathrm{P}=0.04)$. However, no significant relation was noted between 


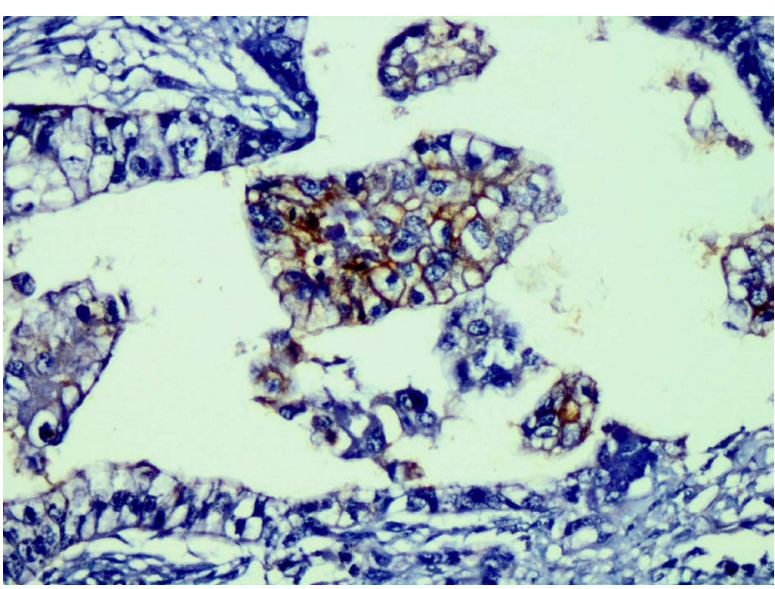

(a)

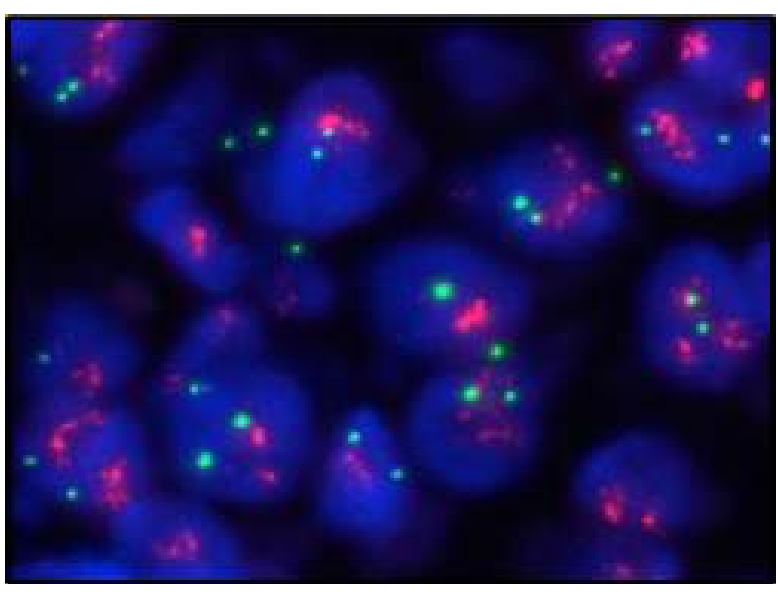

(b)

Figure 1. (a) HER-2/neu moderate to strong complete membranous immunostaining in $<10 \%$ of tumor cells in an intestinal-type gastric carcinoma; IHC score 2+ $(\times 400)$; (b) FISH image of the same tumor seen in (a) showing amplified HER-2/neu featuring increased number of red signals $\{$ HER-2/neu $\}$ than green signals $\{$ Cen 17$\}$.

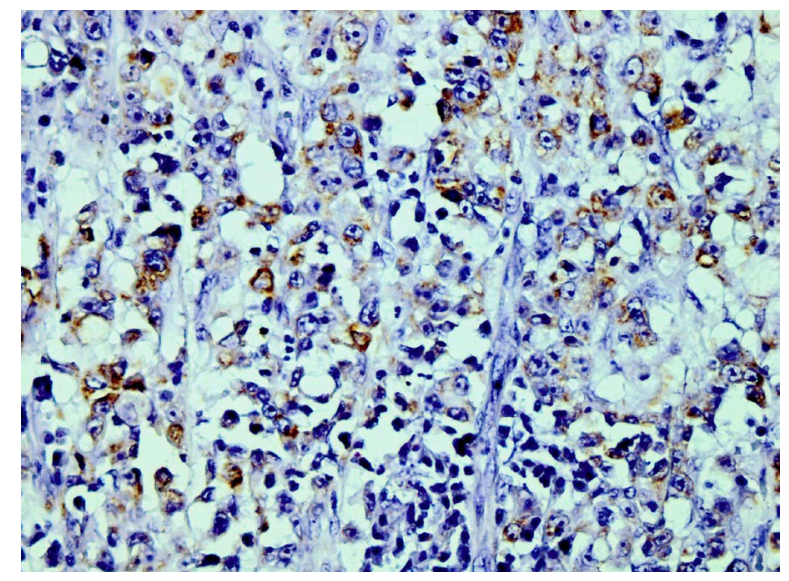

(a)

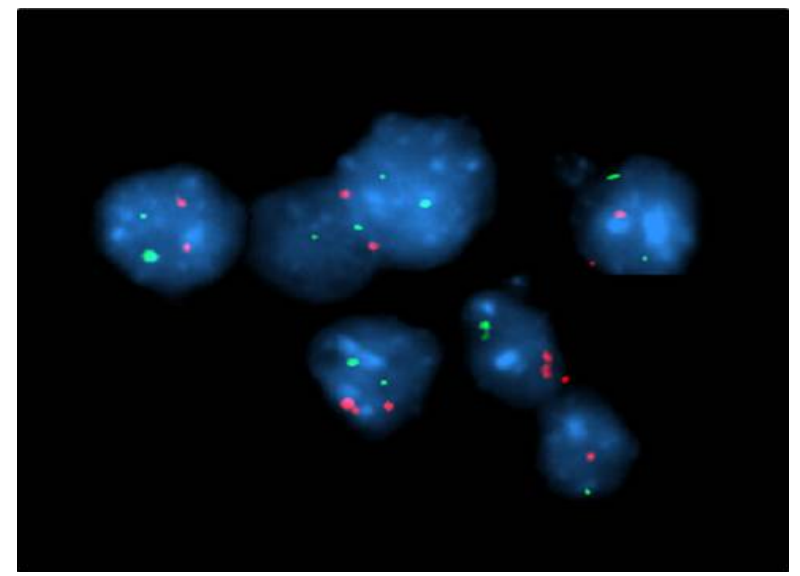

(b)

Figure 2. (a) HER-2/ neu strong complete membranous immunostaining in $<10 \%$ of tumor cells in a diffuse type gastric carcinoma; IHC score $2+(\times 400)$; (b) FISH image of the same tumor seen in (a) showing negative HER-2/neu amplification. Most of the cells show normal pattern of 2 green and 2 red signals.

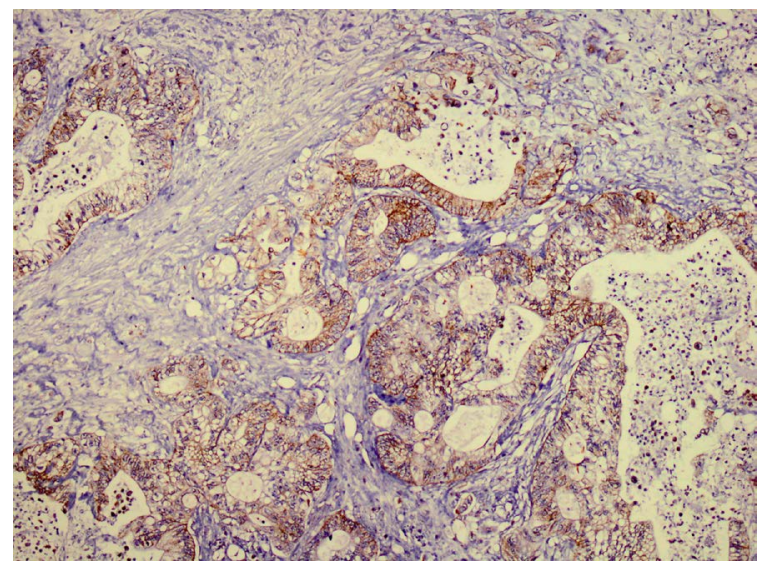

Figure 3. HER-2/neu strong complete membranous immunostaining in most tumor cells in an intestinal-type gastric carcinoma; IHC score $3+(\times 100)$. 


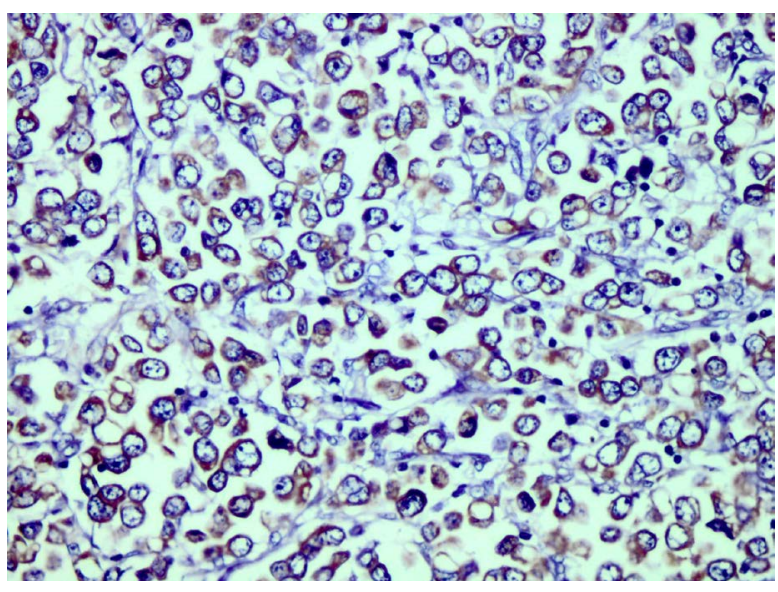

(a)

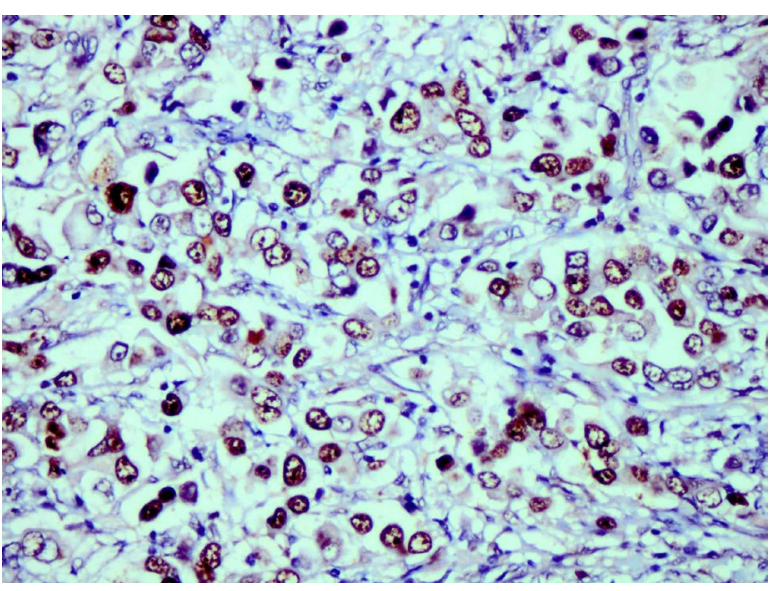

(b)

Figure 4. Diffuse component of a mixed type gastric carcinoma showing HER-2/neu IHC score $3+$ (a) and a high score Ki-67 nuclear staining $(b),(\times 400)$.

the Ki-67 status and any of the other clinicopathological parameters (Table 3).

\subsection{Relationship between Ki-67 Expression and HER-2/Neu Status}

The HER-2/neu IHC expression showed a significant statistical relation with the Ki-67 score $(\mathrm{P}=0.005)$ (Figure 4 and Figure 5). Moreover, a statistically significant correlation was found between HER-2/neu IHC expression and the proliferation index $(\mathrm{r}=0.404 ; \mathrm{P}=0.001)$. However, the overall HER-2/neu positivity (HER2/neu IHC 3+, HER-2/neu IHC 2+/FISH positive) failed to show a significant relation with high Ki-67 score $(\mathrm{P}=0.105)$.

Tumors that showed combined HER-2/neu positivity and high Ki-67 score (20 cases) were significantly associated with higher pathologic T-stage $(\mathrm{P}=0.025)$ and LVI $(\mathrm{P}=0.004)$ (Figure 6), when compared to the remaining 53 cases.

\section{Discussion}

According to a recent Egyptian study, the median overall survival, disease-free survival and progression-free survival for GC patients are 6,17 and 3 months, respectively [16].

The frequency of HER2/neu positivity in GC as well as its relationship to the different clinicopathological parameters has not been studied before in Egyptian patients. Therefore, we underwent this study as an initial step to introduce the routine assessment of HER2/neu status as well as the treatment by trastuzumab as a standard of care among our GC patients.

We observed HER2/neu protein overexpression (HER2/neu IHC $3+$ ) in $13.7 \%(n=10)$ of GCs, and the overall HER2/neu positivity rate (IHC $3+$ or IHC $2+$ FISH positive) was $28.8 \%(\mathrm{n}=21)$. These rates are comparable to those of the ToGA trial, that reported HER2/neu-positive rates (IHC $3+$ or IHC $2+$ /FISH positive) in GC or gastro-esophageal junction (GEJ) cancer patients of $22.1 \%$ overall and around $10.4 \%$ of IHC $3+$ in resected samples [17].

The concordance of protein expression and gene amplification of HER2/neu in GC, in opposition to breast carcinoma is controversial. Protein overexpression without amplification was previously reported by Lemoine $e t$ al. [18], and Kameda et al. [19], which indicates that gene amplification may not be the primary mechanism by which the HER2/neu protein is overexpressed in GC. HER2/neu overexpression may be due to transcriptional activation by other genes or post-transcriptional events [20]. Recent studies, however, report a high concordance between overexpression in IHC and amplification by FISH or CISH [17] [21]. We report a concordance rate of $47.8 \%$ between IHC and FISH for HER2/neu IHC 2+ cases. This is slightly lower than that reported by Yano et al. [21] who found a concordance rate of $58.5 \%$ between IHC and FISH in the IHC 2+ tumors. In the ToGA trial, the overall concordance between HER2/neu positivity by IHC and FISH was $87 \%$ and differences were largely due to FISH-positive cases that were IHC 0/1+ [22]. However, we were not able to assess the overall concordance 
Table 3. Relation between Ki-67 labeling index and clinicopathological variables in the 73 studied cases.

\begin{tabular}{|c|c|c|c|c|c|}
\hline & \multicolumn{4}{|c|}{ Ki-67 labeling index } & \multirow{3}{*}{$\begin{array}{c}\text { Test } \\
\text { significance }\end{array}$} \\
\hline & \multicolumn{2}{|c|}{ Low Ki-67 score } & \multicolumn{2}{|c|}{ High Ki-67 score } & \\
\hline & No. & $\%$ & No. & $\%$ & \\
\hline \multicolumn{6}{|l|}{ Age } \\
\hline$<50$ & 6 & 54.5 & 25 & 40.3 & \multirow{2}{*}{$\begin{array}{c}0.77^{\dagger} \\
\mathrm{P}=0.29\end{array}$} \\
\hline$\geq 50$ & 5 & 45.5 & 37 & 59.7 & \\
\hline \multicolumn{6}{|l|}{ Sex } \\
\hline Male & 3 & 27.3 & 38 & 61.3 & \multirow{2}{*}{$\begin{array}{c}4.39^{\ddagger} \\
\mathbf{P}=\mathbf{0 . 0 3 9}\end{array}$} \\
\hline Female & 8 & 72.7 & 24 & 38.7 & \\
\hline \multicolumn{6}{|l|}{ Histological type } \\
\hline Intestinal & 10 & 90.9 & 45 & 72.6 & \multirow{3}{*}{$\begin{array}{c}1.744^{\ddagger} \\
\mathrm{P}=0.418\end{array}$} \\
\hline Diffuse & 1 & 9.1 & 15 & 24.2 & \\
\hline Mixed & 0 & 0.0 & 2 & 3.2 & \\
\hline \multicolumn{6}{|l|}{ Histological grade } \\
\hline Moderately differentiated & 10 & 90.9 & 32 & 51.6 & \multirow{2}{*}{$\begin{array}{c}5.90^{\ddagger} \\
\mathbf{P}=\mathbf{0 . 0 1 4}\end{array}$} \\
\hline Poorly differentiated & 1 & 9.1 & 30 & 48.4 & \\
\hline \multicolumn{6}{|l|}{ Pathologic tumor stage } \\
\hline $\mathrm{T} 1,2$ & 2 & 18.2 & 12 & 19.4 & \multirow{2}{*}{$\begin{array}{c}0.01^{\ddagger} \\
\mathrm{P}=0.92\end{array}$} \\
\hline $\mathrm{T} 3,4$ & 9 & 81.8 & 50 & 80.6 & \\
\hline \multicolumn{6}{|l|}{ Lymph node metastasis } \\
\hline Present & 8 & 27.3 & 44 & 71.0 & \multirow{2}{*}{$\begin{array}{c}0.014 \\
\mathrm{P}=0.609\end{array}$} \\
\hline Absent & 3 & 72.7 & 18 & 29.0 & \\
\hline \multicolumn{6}{|l|}{ Pathologic Nodal stage } \\
\hline $\begin{array}{l}\text { N0 } \\
\text { N1 } \\
\text { N2 } \\
\text { N3 }\end{array}$ & $\begin{array}{l}3 \\
3 \\
2 \\
3\end{array}$ & $\begin{array}{l}27.3 \\
27.3 \\
18.1 \\
27.3\end{array}$ & $\begin{array}{l}18 \\
10 \\
17 \\
17\end{array}$ & $\begin{array}{l}29.03 \\
16.13 \\
27.42 \\
27.42\end{array}$ & $\begin{array}{c}0.968^{\ddagger} \\
\mathrm{P}=0.809\end{array}$ \\
\hline \multicolumn{6}{|c|}{ Number of nodes with metastasis } \\
\hline $\begin{array}{l}\text { Range } \\
\text { Median }\end{array}$ & \multicolumn{2}{|c|}{$\begin{array}{c}0-5 \\
1.8\end{array}$} & \multicolumn{2}{|c|}{$\begin{array}{c}0-27 \\
5.0\end{array}$} & $\begin{array}{c}3.28^{\S} \\
\mathbf{P}=\mathbf{0 . 0 4}\end{array}$ \\
\hline \multicolumn{6}{|l|}{ Lymphovascular invasion } \\
\hline Present & 7 & 63.6 & 45 & 72.6 & \multirow{2}{*}{$\begin{array}{c}0.365^{\ddagger} \\
\mathrm{P}=0.391\end{array}$} \\
\hline Absent & 4 & 36.4 & 17 & 27.4 & \\
\hline
\end{tabular}

"Significant at $\mathrm{P} \leq 0.05 ;{ }^{\dagger}$ Chi Square test; ${ }^{\star}$ Fisher exact test; ${ }^{\S}$ Mann whitney U test.

of protein expression and gene amplification of HER2/neu in GC, and compare it to others as FISH testing was not done for all cases due to financial limitations.

The prognostic relevance of HER2/neu status in GC is still controversial. In our study, similar to others [23] [24], no relation was found between HER2/neu positivity and patients' age, gender, and pathologic N stage. However, the HER2/neu positive status was significantly associated with LVI $(\mathrm{P}=0.02)$ and the pathologic Tstage $(\mathrm{P}=0.026)$.

Among the 73 studied cases, the intestinal type GC cases showed the highest rate of HER2/neu positivity (IHC 3+, or IHC 2+/FISH positive), yet without statistical significance. Conversely, several studies reported a statistically significant association between HER2/neu-positivity and intestinal-type GC [25]-[27]. In the ToGA 


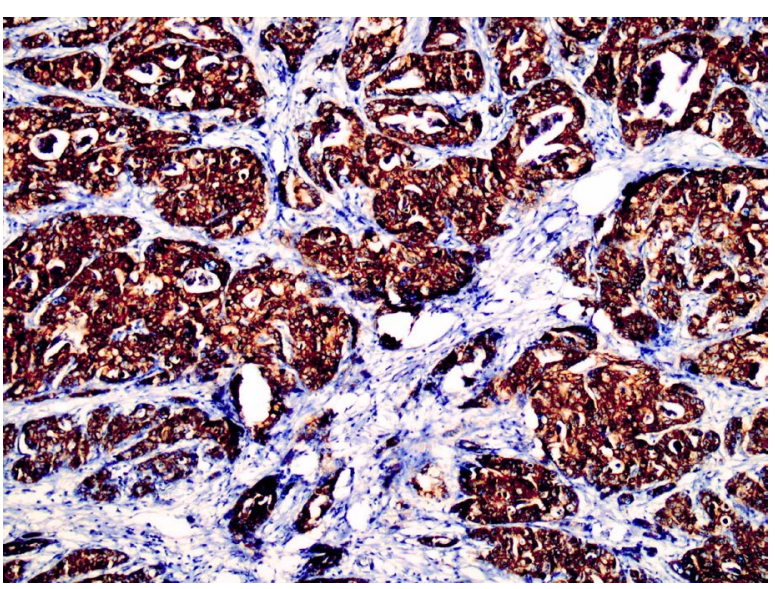

(a)

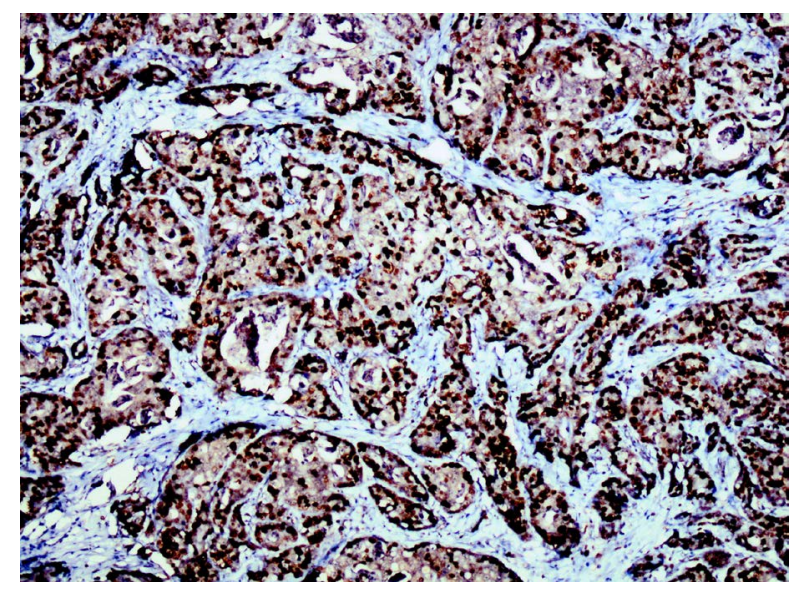

(b)

Figure 5. An intestinal-type gastric carcinoma showing HER-2/neu strong complete membranous immunostaining in almost all tumor cells; IHC score $3+($ a) and a high Ki-67 score $(b)(\times 100)$.

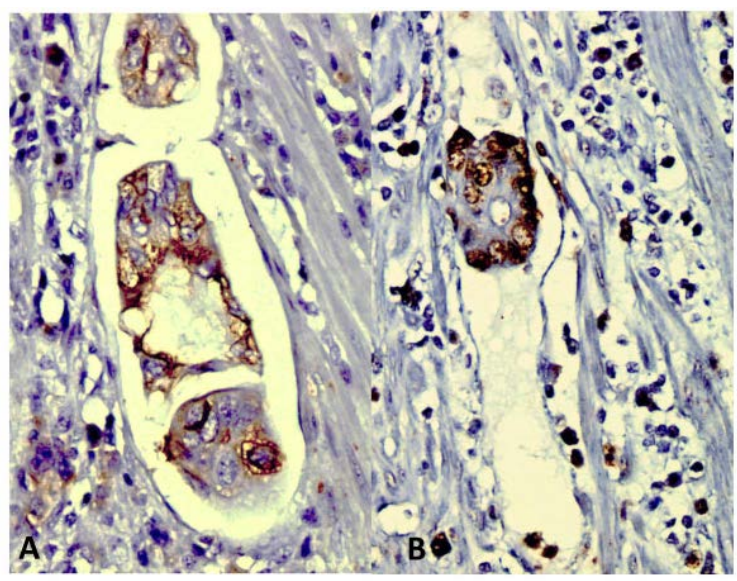

Figure 6. Lymphovascular invasion in an intestinal-type carcinoma showing a score 3+ HER-2/neu immunostaining (a) as well as a high score Ki-67 nuclear staining (b) $(\times 400)$.

trial, countries with higher ratios of intestinal: diffuse/mixed cancer had increased HER2/neu-positivity rates [17], as HER2/neu positivity differed significantly by histological subtype (intestinal $34 \%$, diffuse $6 \%$, mixed 20\%) [26]. In opposition to previous studies [27] [28], HER2/neu positivity in our series did not relate significantly with tumor grade. This contradiction may be due to different sample sizes, or differences in the scoring schemes with different cut-off points that were used prior to the establishment of a standard guideline for assessing HER2/neu expression. The adoption of the current consistent guidelines for HER2/neu assessment in future studies might clarify this issue.

Our second aim was to determine whether the expression of HER2/neu is associated with a more aggressive behavior by its correlation with Ki-67 expression. The Ki-67 expression rate in our study ranged between 10 and $100 \%$, with $84.9 \%$ of the cases $(n=62)$ featuring high Ki-67 scores.

An increased frequency of high Ki-67 score was noted in patients $>50$ years but without statistical significance. This observation is similar to results from previous studies [9] [29] [30]. In accordance with one study [9], but in opposition to others [29] [30] we noted a significantly greater frequency of GCs with high Ki-67 score in male patients $(\mathrm{P}=0.039)$.

We observed a high Ki-67 score among $76.2 \%$ of our studied grade two GCs. In a significantly greater percentage, $96.8 \%$ of poorly differentiated carcinomas featured high Ki-67 score $(\mathrm{P}=0.014)$. These results are concordant with the results from previous studies [9] [29] [30]. Moreover, high Ki-67 score showed a statistically significant correlation with the number of nodes (as a continuous variable) featuring metastatic deposits 
$(\mathrm{P}=0.04)$. This relationship was previously reported in other organs [31] [32]. Similar to Amrani et al. [9], we observed higher rates of high Ki-67 score among higher pT-stages $(91.5 \%$ for $\mathrm{pT} 3$ and $\mathrm{pT} 4$ tumors versus $57.1 \%$ for $\mathrm{pT} 1$ and $\mathrm{pT} 2$ tumors) but without statistical significance. These results suggest that the changes in the proliferative activity of tumor cells are related to the progression of GC. Conversely, Xiao et al. [30] noted the absence of a significant difference in the proliferation rate between Tis/ pT1 tumors and pT2-4 tumors.

We noted that the HER2/neu IHC protein expression correlated significantly and strongly with the Ki-67 in$\operatorname{dex}(r=404 ; p=0.001)$, but the overall HER2/neu positive status did not relate significantly with the Ki-67 score. Similarly, Wu et al. [29] demonstrated that the protein expression and gene amplification of HER2/neu were closely related to the expression of Ki-67 protein.

In this study, the twenty cases that showed both HER2/neu positivity and high Ki67 score revealed a significantly higher T-stage $(P=0.025)$, and higher rates of occurrence of LVI $(P=0.004)$, which signifies greater invasiveness and a more aggressive tumor phenotype. The simultaneous overexpression of HER2/neu and Ki-67 was previously suggested to be a prognostic marker for poor outcome in other tumors [33]-[35].

\section{Conclusion}

In conclusion, we report a rate of HER-2/neu positive GCs of $28.8 \%$, a value close to that reported universally. Therefore, we recommend that, similar to breast cancer specimens, all GC specimens submitted to our laboratory be routinely evaluated for HER-2/neu status. This may give the patient a chance to benefit from trastuzumab therapy. Moreover, tumors showing concurrent HER-2/neu positivity and high Ki-67 score were significantly associated with LVI and higher T-stage, implying a more aggressive behavior. Further studies on a larger number of GCs are required to prove that the concurrent HER-2/neu positivity and high Ki-67 score are markers of worse prognosis.

\section{Authors' Contributions}

Design of the study: MA. Collection of samples: SE, IT. Immunohistochemical analysis: SE, MA. FISH analysis: IT. Statistical analysis and elaboration of manuscript: SE. Critical review of the manuscript: MA. All authors read and approved the final manuscript.

\section{Conflict of Interest}

None.

\section{Source of Support}

None.

\section{References}

[1] Guggenheim, D.E. and Shah, M.A. (2013) Gastric Cancer Epidemiology and Risk Factors. Journal of Surgical Oncology, 107, 230-236. http://dx.doi.org/10.1002/jso.23262

[2] Alieldin, N. (2002-2010) NCI Hospital-Based Registry.

[3] Ferlay, J., Soerjomataram, I., Ervik, M., Dikshit, R., Eser, S., Mathers, C., et al. (2013) GLOBOCAN 2012 v1.0. Cancer Incidence and Mortality Worldwide: IARC Cancer Base No. 11. International Agency for Research on Cancer, Lyon. http://globocan.iarc.fr/Pages/references.aspx

[4] McGrath, SC., Ebert, M. and Röcken, C. (2007) Gastric Adenocarcinoma: Epidemiology, Pathology and Pathogenesis. Cancer Therapy, 5, 877-894.

[5] Yan, S.Y., Hu, Y., Fan, J.G., Tao, G.Q., Lu, Y.M., Cai, X., Yu, B.H. and Du, Y.Q. (2011) Clinicopathologic Significance of HER-2/Neu Protein Expression and Gene Amplification in Gastric Carcinoma. World Journal of Gastroenterology, 17, 1501-1506. http://dx.doi.org/10.3748/wjg.v17.i11.1501

[6] Ross, J.S., Slodkowska, E.A., Symmans, W.F., Pusztai, L., Ravdin, P.M. and Hortobagyi, G.N. (2009) The HER-2 Receptor and Breast Cancer: Ten Years of Targeted Anti-HER-2 Therapy and Personalized Medicine. Oncologist, 14, 320-368. http://dx.doi.org/10.1634/theoncologist.2008-0230

[7] Ross, J.S. and McKenna, B.J. (2001) The HER-2/Neu Oncogene in Tumors of the Gastrointestinal Tract. Cancer Invest, 19, 554-568. http://dx.doi.org/10.1081/CNV-100103852 
[8] Bang, Y.J., Van Cutsem, E., Feyereislova, A., Chung, H.C., Shen, L., Sawaki, A., Lordick, F., Ohtsu, A., Omuro, Y., Satoh, T., Aprile, G., Kulikov, E., Hill, J., Lehle, M., Rüschoff, J. and Kang, Y.K., ToGA Trial Investigators (2010) Trastuzumab in Combination with Chemotherapy versus Chemotherapy Alone for Treatment of HER2-positive Advanced Gastric or Gastro-Oesophageal Junction Cancer (ToGA): A Phase 3, Open-Label, Randomised Controlled Trial. The Lancet, 376, 687-697. http://dx.doi.org/10.1016/S0140-6736(10)61121-X

[9] Amrani, H.J.,Marchoudi, N., Sadaoui,I., Mahfoud, W., Elgnaoui, N., Haddad, F., Fechtali, T. and Benomar, H. (2014) Ki-67 Expression in Gastric Cancer and Correlation with Clinico-Pathological Characteristics. International Journal of Scientific and Research Publications, 4, 1-4.

[10] Czyzewska, J., Guzińska-Ustymowicz, K., Pryczynicz, A., Kemona, A. and Bandurski, R. (2009) Immunohistochemical Evaluation of Ki-67, PCNA and MCM2 Proteins Proliferation Index (PI) in Advanced Gastric Cancer. Folia Histochemica Et Cytobiologica, 47, 289-296. http://dx.doi.org/10.2478/v10042-009-0042-y

[11] Endl, E. and Gerdes, J. (2000) The Ki-67 Protein: Fascinating Forms and an Unknown Function. Experimental Cell Research, 257, 231-237. http://dx.doi.org/10.1006/excr.2000.4888

[12] Fred, T., Carneiro, B.F., Hruban, R.H. and Theise, N.D. (2010) WHO Classification of Tumours of the Digestive System. 4th Edition, IARC, Lyon, 417p.

[13] Washington, K. (2010) 7th Edition of the AJCC Cancer Staging Manual: Stomach. Annals of Surgical Oncology, 17, 3077-3079. http://dx.doi.org/10.1245/s10434-010-1362-z

[14] Hofmann, M., Stoss, O., Shi, D., Buttner, R., van de Vijver, M., Kim, W., Ochiai, A., Ruschoff, J. and Henkel, T. (2008) Assessment of a HER2 Scoring System for Gastric Cancer: Results from a Validation Study. Histopathology, 52, 797-805. http://dx.doi.org/10.1111/j.1365-2559.2008.03028.x

[15] Dowsett, M., Nielsen, T.O., A’Hern, R., Bartlett, J., Coombes, R.C., Cuzick, J., Ellis, M., Henry, N.L., Hugh, J.C., Lively, T., McShane, L., Paik, S., Penault-Llorca, F., Prudkin, L., Regan, M., Salter, J., Sotiriou, C., Smith, I.E., Viale, G., Zujewski, J.A. and Hayes, D.F. (2011) Assessment of Ki67 in Breast Cancer: Recommendations from the International Ki67 in Breast Cancer Working Group. Journal of the National Cancer Institute, 103, 1656-1664. http://dx.doi.org/10.1093/jnci/djr393

[16] Zeeneldin, A.A., Ramadan, H., El Gammal, M.M., Saber, M.M., Elgamal, D. and Sherisher, M.A. (2014) Gastric Carcinoma at Tanta Cancer Center: A Comparative Retrospective Clinico-Pathological Study of the Elderly versus the Non-Elderly. Journal of the Egyptian National Cancer Institute, 26,127-137. http://dx.doi.org/10.1016/j.jnci.2014.04.002

[17] Bang, Y., Chung, H., Xu, J., Lordick, F., Sawaki, A., Al-Sakaff, N., Lipatov, O., See, C., Rueschoff, J. and Van Cutsem, E. (2009) Pathological Features of Advanced Gastric Cancer (GC): Relationship to Human Epidermal Growth Factor Receptor 2 (HER2) Positivity in the Global Screening Program of the ToGA Trial. Journal of Clinical Oncology, 27, $15 \mathrm{~S}$.

[18] Lemoine, N.R., Jain, S., Silvestre, F., Lopes, C., Hughes, C.M., McLelland, E., Gullick, W.J. and Filipe, M.I. (1991) Amplification and Overexpression of the EGF Receptor and c-erbB-2 Proto-Oncogenes in Human Stomach Cancer. British Journal of Cancer, 64, 79-83. http://dx.doi.org/10.1038/bjc.1991.243

[19] Kameda, T., Yasui, W., Yoshida, K., Tsujino, T., Nakayama, H., Ito, M., Ito, H. and Tahara, E. (1990) Expression of ERBB2 in Human Gastric Carcinomas: Relationship between p185ERBB2 Expression and the Gene Amplification. Cancer Research, 50, 8002-8029.

[20] Hollywood, D.P. and Hurst, H.C. (1993) A Novel Transcription Factor, OB2-1, Is Required for Overexpression of the Proto-Oncogene c-erbB-2 in Mammary Tumour Lines. The EMBO Journal, 12, 2369-2375.

[21] Yano, T., Ochiai, A. and Doi, T. (2004) Expression of HER2 in Gastric Cancer: Comparison between Protein Expression and Gene Amplification Using a New Commercial Kit. Journal of Clinical Oncology, 22, 14S.

[22] Lordick, F., Bang, Y.J., Kang, Y.K., et al. (2007) HER2-Positive Advanced Gastric Cancer: Similar HER2-Positivity Levels to Breast Cancer. European Journal of Cancer, 5, 271.

[23] Kataoka, Y., Okabe, H., Yoshizawa, A., Minamiguchi, S., Yoshimura, K., Haga, H. and Sakai, Y. (2012) HER2 Expression and Its Clinicopathological Features in Resectable Gastric Cancer. Gastric Cancer, 16, 84-93. http://dx.doi.org/10.1007/s10120-012-0150-9

[24] Bozzetti, C., Negri, F.V., Lagrasta, C.A., Crafa, P., Bassano, C., Tamagnini, I., Gardini, G., Nizzoli, R., Leonardi, F., Gasparro, D., Camisa, R., Capelli, S., Silini, E.M. and Ardizzoni, A. (2011) Comparison of HER2 Status in Primary and Paired Metastatic Sites of Gastric Carcinoma. British Journal of Cancer, 104, 1372-1376. http://dx.doi.org/10.1038/bjc.2011.121

[25] Gravalos, C. and Jimeno, A. (2008) HER2 in Gastric Cancer: A New Prognostic Factor and a Novel Therapeutic Target. Annals of Oncology, 19, 1523-1529. http://dx.doi.org/10.1038/bjc.2011.121

[26] Zhang, X.L., Yang, Y.S., Xu, D.P., Qu, J.H., Guo, M.Z., Gong, Y. and Huang, J. (2009) Comparative Study on Over- 
expression of HER2/Neu and HER3 in Gastric Cancer. World Journal of Surgery, 33, 2112-2118. http://dx.doi.org/10.1007/s00268-009-0142-Z

[27] Kim, K.C., Koh, Y.W., Chang, H.M., Kim, T.H., Yook, J.H., Kim, B.S., Jang, S.J. and Park, Y.S. (2011) Evaluation of HER2 Protein Expression in Gastric Carcinomas: Comparative Analysis of 1,414 Cases of Whole-Tissue Sections and 595 Cases of Tissue Microarrays. Annals of Surgical Oncology, 18, 2833-2840. http://dx.doi.org/10.1245/s10434-011-1695-2

[28] Wu, H.M., Liu, Y.H., Lin, F., Xu, F.P., Luo, D.L., Zhang, F., Zhuang, H.G., Luo, X.L., Wu, W.L. and Lin, X.T. (2011) Association of HER2 Protein Expression with Clinicopathologic Features and Prognosis in Chinese Patients with Gastric Carcinoma. Chinese Journal of Pathology, 40, 296-299.

[29] Wu, H.W., Qin, C.Y., Huang, J.L., Kong, X.Y., Wang, W.J. and Bai, W.K. (2014) Correlations of $\beta$-Catenin, Ki67 and Her-2/Neu with Gastric Cancer. Asian Pacific Journal of Tropical Medicine, 7, 257-261. http://dx.doi.org/10.1016/S1995-7645(14)60033-X

[30] Xiao, L.J., Zhao, S., Zhao, E.H., Zheng, X., Gou, W.F., Takano, Y. and Zheng, H.C. (2013) Clinicopathological and Prognostic Significance of Ki-67, Caspase-3 and p53 Expression in Gastric Carcinomas. Oncology Letters, 6, 12771284.

[31] Protzel, C., Knoedel, J., Zimmermann, U., Woenckhaus, C., Poetsch, M. and Giebel, J. (2007) Expression of Proliferation Marker Ki67 Correlates to Occurrence of Metastasis and Prognosis, Histological Subtypes and HPV DNA Detection in Penile Carcinomas. Histology and Histopathology, 22, 1197-1204.

[32] Yin, Y., Zeng, K., Wu, M., Ding, Y., Zhao, M. and Chen, Q. (2014) The Levels of Ki-67 Positive Are Positively Associated with Lymph Node Metastasis in Invasive Ductal Breast Cancer. Cell Biochemistry and Biophysics, 70, 11451151. http://dx.doi.org/10.1007/s12013-014-0034-1

[33] Rakovitch, E., Nofech-Mozes, S., Hanna, W., Narod, S., Thiruchelvam, D., Saskin, R., Spayne, J., Taylor, C. and Paszat, L. (2012) HER2/Neu and Ki-67 Expression Predict Non-Invasive Recurrence Following Breast-Conserving Therapy for Ductal Carcinoma in Situ. British Journal of Cancer, 106, 1160-1165. http://dx.doi.org/10.1038/bjc.2012.41

[34] Nguyen, L.H., Black, M.J., Hier, M., Chauvin, P. and Rochon, L. (2003) HER2/Neu and Ki-67 as Prognostic Indicators in Mucoepidermoid Carcinoma of Salivary Glands. The Journal of Otolaryngology, 32, 328-331. http://dx.doi.org/10.2310/7070.2003.11438

[35] Lukashina, M.I., Glukhova, E.I., Zhukova, L.G., Ermilova, V.D., Bogatyrev, V.N. and Baryshnikov, A.I. (2003) Her-2/Neu, Ki-67 Expression and Ploidy in Breast Carcinoma. Archives of Pathology, 65, 25-29.

\section{List of Abbreviations}

CEP: Centromere Enumeration Probe

FISH: Fluorescent in Situ Hybridization

GC: Gastric Carcinoma

GCSS: Gastric Cancer Scoring System

IHC: Immunohistochemistry

LSI: Locus Specific Identifier

LVI: Lymphovascular Invasion

ToGA: Trastuzumab for Gastric Cancer 